\title{
Message from the Editor-in-Chief
}

\author{
Dr Ingrid Harrington
}

To cite this article: Dr Ingrid Harrington. (2021). Message from the Editor-in-Chief. International Journal of Higher Education, 10(6), p0-2. https://doi.org/10.5430/ijhe.v10n6p0

doi:10.5430/ijhe.v10n6p0 URL: https://doi.org/10.5430/ijhe.v10n6p0

Higher education institutions continue to play a fundamental, unique and core role in seeking and pursuing a vision for education and training that celebrates cultural difference. We are proud to present this issue with 21 contributions from South Africa, Hong Kong, Jordan, the United States, India, Ecuador, Kuwait, Saudi Arabia, Israel, Sweden and Canada. The pandemic continues to challenge all educators, particularly those in tertiary settings where learning and teaching remotely presents its own set of challenges. This issue has a strong focus on conflict management, strategic capabilities and the academic performance of students in higher education. Research on assessment, leadership, the sociocultural environment of inclusion, and the professional development of educators, will provide interesting and informative reading, on how global educators continue with their core business of delivering relevant and meaningful education.

The first article by Lukman focuses on the conflicting variables of an Eastern Cape University in South Africa, that contributes to the annual student protests and demonstrations at the beginning of every academic year, adversely impacting the smooth running of academic programs. The findings highlighted two major variables that give rise to conflicts, escalation of strikes, and demonstrations at Higher Institutions of learning, and recommend a conflict management style approach for handling the situation. Chen and Chan's article reports on their research designed to enhance students' creative problem-solving ability using a project-based learning approach. Their results showed that the students' creative problem-solving ability was effectively enhanced by the intervention of project-based learning, especially in terms of identifying problems, finding solutions and evaluating them. Al-zboon, et.al's research examined the effect of multiple-choice test items' difficulty degree on the reliability coefficient and the standard error of measurement, depending on the Item Response Theory. Their results found that there were differences between the test reliability parameters attributed to the difficulty degree of the test according to the three-parameter model, in favour of the form with the average difficulty degree. The fourth article by Azzarello and colleagues examined the perceived effectiveness of real-world applicability in undergraduate degrees, and found that alumni felt the relationships formed had a greater contribution to their life-readiness compared to their real-world curriculum. Other emerging themes revealed alumni believed they developed valuable skills through hands-on experience and group work. The next article in this issue by Phunaploy, Chatwattana and Piriyasurawong systematically reviewed the conceptual framework of the problem-based learning process with a cloud learning environment (PBL-CLE process). Their article identified that the PBL-CLE process consists of four components, and the process includes problem posing, problem analysis, problem understanding, research procedure, knowledge synthesis, conclusion and evaluation, presentation, and assignment assessment. The sixth article in this issue is from Ahmed et.al., and they discuss the recent updates and developments of computing-based courses in the civil engineering discipline in Saudi Arabia. Their findings provide input and suggestions for future upgrades of computing-based courses offered within the civil engineering curriculum.

The seventh article by Mncube and associates examines the novice teachers' use of English as the medium of instruction in curriculum delivery across all subjects in rural South African schools. Their findings indicate that the educational backgrounds of learners hinder teachers' use of English to teach them meaningfully. The teachers also found it convenient to use indigenous languages to deliver lesson content or communicate to these learners in the classrooms during lessons, and that some teachers struggled to express themselves in English due to their educational backgrounds. The next article by Ponce and Cedeno considered the impact of a program to send 
Ecuadorian students to undertake postgraduate studies at universities overseas, specifically, women, the low-income group, and those beneficiaries that studied in the USA. This article evaluates the impact of this grant policy on the labour income of the beneficiaries after they have completed their studies abroad and returned to Ecuador.

Olawale, Mncube and Harber's research investigated the pedagogical approaches which mathematics teacher educators employed in the development of democratic citizens in South African universities. Their findings recommend that mathematics teacher educators employ a problem-posing pedagogical approach which allows for the appropriation of knowledge in the form of self-reflection, a synergy of care, and self-determination which seeks to foster democratic values and critical consciousness in the development of democratic citizens. Samad and Harripersaud's study charts the efforts made by various countries to deal with the impact of education on schools, colleges and universities. Their findings propose a solution that involves the re-imagining and re-designing of the traditional classroom space into being a Teaching and Learning Station, that almost guarantees the safe re-opening of schools. The eleventh article by Talal Almesad determined the suitability level for the Faculties and Institutes' graduates of the Public Authority for Applied Education and Training and the requirements of the labour market in Kuwait, from the perspective of employers in the public and private sectors. The results showed that the suitability level of graduates and the requirements of the labour market Kuwait were moderate, favoured female employees and the public work sector. Research by Matarirano and colleagues identified the ICT platforms and approaches used by lecturers during remote teaching, and estimated the readiness of students for emergency remote learning. The study found that Microsoft teams was the commonly used platform whilst pre-recorded lectures and live classes were the popular approaches used.

The thirteenth article by Kemda and Murray explores students' attrition longitudinally from a student's given course of study, from enrolment to exit from the university through degree completion and academic dropout. Their findings report that factors such as financial aid, matriculation points, students' race, course type registered, and gender are distinguishing factors that affect students' academic performances, for completers and dropouts. The next article by Kidushin, Kushnir and Davidovitch investigates the association between motivation and perceived meaning in one's job satisfaction and intention to leave, among care workers in out-of-home facilities for people with intellectual and developmental disabilities (IDD). Their findings highlight the importance of placing skilled educated personnel in caregiving roles among the disabled in general, and those with IDD living in out-of-home facilities. Additionally, the necessity to strengthen the ties between academic education and actual reality of working in the field with people with disabilities. The fifteenth article by Kexin Wang analyzes the differences between the communication and social information dissemination in the era of all media and the past, specifically how universities innovate the incentive mechanism for the development of teacher education, and how university teachers themselves seize the opportunity of this era to improve themselves. The next article by Sirvan Karimi explores the challenges facing Canadian higher educational institutions in their endeavour to strike a balance between promoting diversity, inclusion and respecting free speech, in order to preserve the socially vital mission of universities and promote the public trust in the higher educational institutions. Central to the contention revolving around the free speech debate is an assertion that institutional pressures for consolidating a culture of political correctness is believed to have the potential to curtail and stifle freedom of expression, which has in turn triggered governmental intervention in certain Canadian provinces. Amoke, et.al's study investigated the interaction effect gender has on academic procrastination and achievement orientation among in-school adolescents. Their study reported that gender does not significantly have a negative effect on in-school adolescents' academic procrastination and achievement orientation, and that government agencies and professional bodies whose responsibility is to design and revise curriculum for secondary schools, should incorporate and emphasize the use of rational emotive behavioural therapy in secondary schools. The second last article by Edyta examines which teaching content, teaching methods, learning activities, teacher's role, and students' own strategies for learning in an international blended, face-to-face and online Master's Program, work best in Sweden. Her findings report how Campus and online phases of the Program mattered for students' learning, and she indicates the challenges related to online study and educational methods that may help to overcome them. This issue ends with timely and relevant research by Mncube and associates who explored both the social inclusion and the social exclusion of ICT with users appropriating of Open Educational Resources in open distance e-learning (ODeL) institutions. Some of their findings report that inequalities still exist, as the innovation enabled through the utilisation of ICT tends to favour 
a select minority of rich people, hence, for many students, ICT continues to perpetuate social exclusion. Their study recommends the development of initiatives to close the current gaps which contribute to the social exclusion.

I sincerely hope that the broad range of topics and information shared are of benefit to our readers. Importantly, I would like to thank all contributors and reviewers who continue to make the timely publication of the current issue possible. We look forward to receiving more contributions from researchers and practitioners for our future issues. Wishing all readers all the very best for the Christmas holiday season and the new 2022 year celebrations!

Warm regards,

Dr Ingrid Harrington

Senior Lecturer, Classroom Behaviour Management

Coordinator, Commencing Student Success Program

School of Education

Faculty of Humanities, Arts, Social Sciences, Education (HASSE)

University of New England, Australia

$\&$

Editor-in-Chief, International Journal of Higher Education

https://orcid.org/0000-0002-1898-4795 